\title{
Indications and Prognosis of the Hysterectomy Operation in the Obstetrics and Gynecology Department at the University Teaching Hospital of Ouagadougou (UTH-YO), Burkina Faso
}

\author{
Ouattara Adama ${ }^{*}$, Kaboré Francois Xavier Gueswendé1, Sib Sansan Rodrigue ${ }^{2}$, \\ Millogo/Traoré Françoise Danielle1, Ouedraogo Issa2 ${ }^{2}$ Touré Boubakar'1, \\ Ouédraogo Ali ${ }^{1}$, Ouédraogo Marie Charlemagne ${ }^{1}$, Thieba/Bonane Blandine ${ }^{1}$ \\ ${ }^{1}$ Gynecologist Obstetrician at the University Teaching Hospital of Ouagadougou, Ouagadougou, Burkina Faso \\ ${ }^{2}$ Gynecologist Obstetrician at the Regional Hospital of Ouahigouya, Ouahigouya, Burkina Faso \\ Email: *ouattzangaadama@yahoo.fr
}

How to cite this paper: Adama, O., Gueswendé, K.F.X., Rodrigue, S.S., Danielle, M.F., Issa, O., Boubakar, T., Ali, O., Charlemagne, O.M. and Blandine, T. (2017) Indications and Prognosis of the Hysterectomy Operation in the Obstetrics and Gynecology Department at the University Teaching Hospital of Ouagadougou (UTH-YO), Burkina Faso. Open Journal of Obstetrics and Gynecology, 7, 1239-1246.

https://doi.org/10.4236/ojog.2017.713126

Received: August 20, 2017

Accepted: December 5, 2017

Published: December 8, 2017

Copyright ( 92017 by authors and Scientific Research Publishing Inc. This work is licensed under the Creative Commons Attribution International License (CC BY 4.0).

http://creativecommons.org/licenses/by/4.0/ (c) (i) Open Access

\begin{abstract}
Objective: To describe the indications and the prognosis of the hysterectomy operation in the obstetrics and gynecology department at the UTH-YO, Ouagadougou, Burkina Faso. Methodology: It has been a descriptive cross-sectional study over a period of 18 months from 1 January 2014 to 30 June 2015 in the obstetrics and gynecology department of the UTH-YO. The variables studied were demographics, clinical and prognostic aspects. Results: During the study period, we recorded 128 cases of hysterectomies including 20 obstetric causes (15.62\%) and 108 gynecological cases (84.38\%). The incidence of hysterectomy was 3 per 1000 births. Gynecological indications were dominated by uterine fibroids (47.3\%), genital prolapse (20.4\%), cervical dysplasia $(9.3 \%)$ and functional bleeding (7.4\%). Obstetric indications were dominated by uterine ruptures $(60 \%)$, the postpartum haemorrhage $(15 \%)$. The prognosis of obstetric indications was marked by 5 cases of bladder lesions or a morbidity rate of $3.9 \%$ and 4 deaths that to say a fatality rate of $3.1 \%$. Conclusion: The prognosis of hysterectomies should be improved with further training of health workers in surgical techniques, the adoption of strategies to reduce maternal mortality and community awareness in attendance at health facilities.
\end{abstract}

\section{Keywords}

Hysterectomy, Indications, Prognosis, Ouagadougou 


\section{Introduction}

Hysterectomy, which involves removal of the uterus, is a common procedure in surgical practice. In France, it is the most common interventions after appendectomy. Performed vaginally or abdominally, the indications are gynecological or obstetrical order. Obstetric hysterectomy is often performed in emergency in order to save the life of the mother. In gynecology, indications are dominated by the tumor, whether benign or malignant [1] [2] [3] [4].

In Burkina Faso, a country in sub-Saharan Africa, the hysterectomy indications were represented by uterine ruptures and benign fibroids tumors [5] [6] [7]. Since 2010, the promotion of screening for precancerous lesions of the uterine cervix by the method of Visual Inspection with Acetic Acid and Iodine (VIA-VIL) has expanded the indications for hysterectomy.

In the absence of data on hysterectomies in the gynecology department of the University Teaching Hospital Yalgado Ouedraogo (UTH-YO) at Ouagadougou, we felt it necessary to initiate this study to define the indications of hysterectomies and assess prognosis.

\section{Methodology}

It has been a transversal descriptive study conducted into the Obstetrics and Gynecology department of the University Teaching Hospital Yalgado Ouedraogo (UTH-YO) at Ouagadougou, from $1^{\text {st }}$ January 2014 to 30 June 2015 or a period of 18 months. Ouagadougou is the capital of Burkina Faso, located in West Africa. Were included in the study, patients who underwent a hysterectomy in the department during the period of the study. The variables studied were demographics, clinical and prognostic aspects.

Data were collected on a survey sheet which has tracked patients from admission until discharge from the hospital. Entry and data analysis were performed on micro PC with 6 GB of Epi Info software. Statistical tests used for data comparison were the usual statistics (mean, proportion, percentage), comparison tests of qualitative variables (chi square test, Fischer test). The significance level was set at $\mathrm{p}<0.05$.

\section{Results}

\subsection{Frequency}

From $1^{\text {st }}$ January 2014 to 30 June 2015, we identified 128 cases of hysterectomy. During this period, 9474 patients were admitted and 3332 surgeries were recorded in the department of gynecology and obstetrics at the UTH-YO. Hysterectomy represented $1.3 \%$ of admissions and $3.8 \%$ of surgeries. The division found 20 hysterectomies for obstetric causes and 108 hysterectomies for gynecological causes in the respective reports of $15.6 \%$ and $84.4 \%$. The number of hysterectomies in obstetrical causes reported for 6459 deliveries recorded during the period of the study that to say a frequency of 3 hysterectomies for 1000 deliveries. 


\subsection{Socio-Demographic Characteristics}

Sociodemographic characteristics are summarized in Table 1.

\subsection{Clinical Aspects}

\subsubsection{Admission Reasons}

The various reasons for admission are summarized in Table 2.

\subsubsection{Indications and Surgical Approach}

Taking into account the surgical approach initially used, the operating data are summarized in Table 3.

\subsubsection{Type of Hysterectomy}

In 109 cases (85.2\%), a total hysterectomy was performed and in 19 cases or $14.8 \%$, it was subtotal. In gynecological indications, hysterectomy was intra-facial and performed abdominally.

\subsubsection{Timing of Surgery}

The mean duration of surgery was 100 minutes with extremes of 45 minutes and 210 minutes. It has been represented in the Figure 1.

\subsubsection{Associated Procedures}

In the abdominally hysterectomy, 31 patients $(24.22 \%)$ received a gesture

Table 1. Sociodemographic characteristics of patients $(n=128)$.

\begin{tabular}{cc}
\hline Settings & Values \\
\hline Middle age (years) & $43.23(16-72)$ \\
Profession & $104(81.3 \%)$ \\
Household & $24(18.7 \%)$ \\
others & \\
Marital status & $89.8 \%$ \\
Married & $6.3 \%$ \\
Widows & $2.3 \%$ \\
Singles & $1.6 \%$ \\
Divorced & $4.88(0-12)$ \\
Mean number of pregnancy & \\
Number of childbirth & $10(7.8 \%)$ \\
0 & $21(16.4 \%)$ \\
$1-2$ & $62(48.4 \%)$ \\
3 - 5 & $35(27.4 \%)$ \\
$>5$ & $98(76.6 \%)$ \\
Geographical origin & $30(23.4 \%)$ \\
Ouagadougou & \\
Others & \\
\hline
\end{tabular}


Table 2. Distribution of patients according to the reason for admission $(n=128)$.

\begin{tabular}{ccc}
\hline reason & Number & Proportion (\%) \\
\hline Gynecological Indications $(\mathrm{n}=\mathbf{1 0 8})$ & 51 & 47.3 \\
Uterine fibroids & 22 & 20.4 \\
Genital prolapse & 10 & 9.3 \\
Cervical dysplasia & 9 & 8.3 \\
Uterine cervical cancer stage I & 8 & 7.4 \\
Genital bleeding & 3 & 2.8 \\
Choriocarcinoma & 1 & 0.9 \\
Endometrial cancer & 1 & 0.9 \\
Ovarian cyst & 1 & 0.9 \\
Uterine malformation & 1 & 0.9 \\
Ovarian tumor & 1 & 0.9 \\
Uterine tumor & & \\
Obstetric Indications $(\mathrm{n}=20)$ & 12 & 60 \\
Uterine rupture & 3 & 15 \\
Postpartum hemorrhage & 1 & 5 \\
Placenta praevia & 1 & 5 \\
Pre rupture uterine & 1 & 5 \\
acromion presentation & 1 & 5 \\
post ceasarean evisceration & 1 & 5 \\
Hydatiform mole & & 5 \\
Total & & 5 \\
\hline
\end{tabular}

Table 3. Distribution of patients according to the surgical indication and the surgery approach $(\mathrm{n}=128)$.

\begin{tabular}{|c|c|c|c|c|}
\hline \multirow{2}{*}{ Indication for surgery } & \multicolumn{2}{|c|}{ Surgical approach } & \multirow{2}{*}{ Total } & \multirow{2}{*}{$\%$} \\
\hline & vaginally & abdominally & & \\
\hline Cancer of the cervix & 0 & 10 & 10 & 7.8 \\
\hline Endometrial Cancer & 0 & 1 & 1 & 0.78 \\
\hline Choriocarcinoma & 0 & 5 & 5 & 3.90 \\
\hline Cervical dysplasia (CIN3) & 2 & 8 & 10 & 7.81 \\
\hline Uterine fibroma & 1 & 52 & 53 & 41.40 \\
\hline Placental abryptio & 0 & 1 & 1 & 0.78 \\
\hline Functional bleeding & 0 & 1 & 1 & 0.78 \\
\hline Postpartum hemorrhage & 0 & 5 & 5 & 3.90 \\
\hline Uterine malformation & 0 & 1 & 1 & 0.78 \\
\hline Uterine necrosis & 0 & 1 & 1 & 0.78 \\
\hline Uterine perforation & 0 & 1 & 1 & 0.78 \\
\hline Polyp delivered by the cervix & 1 & 0 & 1 & 0.78 \\
\hline Polyp in the cavity & 0 & 1 & 1 & 0,78 \\
\hline Genital prolapse & 20 & 1 & 21 & 16.40 \\
\hline Uterine rupture & 0 & 13 & 13 & 10.15 \\
\hline Ovarian tumor & 0 & 3 & 3 & 2.34 \\
\hline Total & 24 & 104 & 128 & $100 \%$ \\
\hline
\end{tabular}




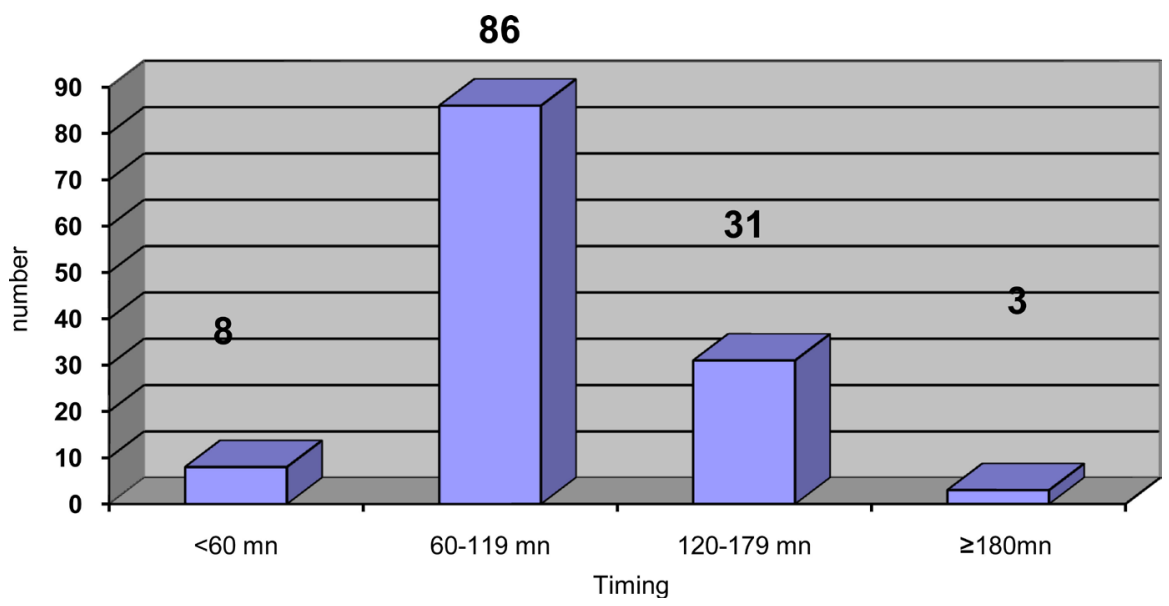

Figure 1. Distribution of patients according to the timing of surgery $(n=128)$.

associated. The complementary gesture most used was oophorectomy in 25 cases. During vaginally hysterectomy, 19 patients or $14.84 \%$ received a gesture associated of perineorrhaphy type. The observed difference was statistically significant $\left(\chi^{2}=17.94 \mathrm{p}\right.$ corrected $\left.=2.10-5\right)$.

\subsection{Prognosis}

\subsubsection{Complications}

Five (5) cases of bladder lesions or $3.9 \%$ of hysterectomy cases including two cases by high way and three, vaginally. Two cases of urogenital fistulas were recorded for a frequency of $1.6 \%$

\subsubsection{Duration of Hospital Stay}

The average hospital stay was 7 days with extremes of 1 and 27 days. The hospital stay was less than eight days in 89 cases (69.5\%). The duration of hospitalization was lower to eight days for $60 \%$ of patients operated vaginally versus $68.2 \%$ of operated abdominally. This difference is not statistically significant $(p=0.07)$.

The study of hospital stay according to the indications clearly shows that the length of stay was longer with obstetric indications $(p=0.003)$.

\subsubsection{Mode of Leaving from Hospital}

One hundred twenty-two (122) patients were left without any complication or 95.3\% in the number of patients operated for hysterectomy. No patient left against medical advice. Four (4) deaths were deplored following obstetric complications case or a fatality rate of $3.1 \%$. Two (02) patients were transferred to the urology department.

\section{Discussion}

The frequency of hysterectomy in our study was 3.8\%. Thus it is substantially equal to the one of Balima [8] in a study conducted from 1996 to 2000, which represented $3.11 \%$ hysterectomy surgery of the obstetrics gynecology department at the UTH-YO. Despite the extension of the methods of early detection of 
precancerous lesions, this frequency seems to remain the same. It should be good to monitor the frequency of hysterectomies to evaluate the impact of the promotion of the management of precancerous lesions in our country.

Our study found a mean age of 43.23 years, ranging from sixteen to seventytwo years in patients operated for hysterectomy; while Kouakou [7] in Cote d'Ivoire found extreme for the vaginally 37 and 61 years with a mean age of patients at 51 years. On 1127 hysterectomies performed in the gynecology department in the hospitals of Grace in Toulouse in France [3], across all lanes, the average age of abdominally hysterectomies was 47.5 years. We notice that in our study, the population was younger. This reflects the lowest life expectation in Burkina Faso; 53 years in urban areas and 48 in rural areas according to national studies.

We recorded twenty four (24) cases of vaginally hysterectomy (18.75\%) and a hundred and four cases by abdominally way (81.25\%). Périneau [3] on 1127 hysterectomies have used vaginally in $31.05 \%$ of cases. This rate is significantly higher than ours, and is explained by the fact that vaginally hysterectomies are recent practice in our department.

For the vaginally way, the indication was genital prolapse in $83.33 \%$ of cases operated. For the abdominally way, the most frequent indications are uterine fibroids in 52 cases (50\%), uterine rupture in 13 cases (12.5\%), 10 cases of cervical cancer $(9.61 \%)$, cervical dysplasia in 8 cases $(7.69 \%), 5$ cases of choriocarcinoma (4.81\%) and 5 cases $(4.81 \%)$ of postpartum hemorrhage. According to Périneau [3], the most frequent indications for the abdominally hysterectomy are the uterine fibroids in $66,7 \%$. Our results are comparable to those of Périneau's in this pattern. The low rate of vaginally hysterectomy for uterine fibroid in our department can be explained by the frequency of large uterine fibroids whose size makes it better for abdominal surgery [2].

The average duration of surgery in our study was 100 minutes. In $67.19 \%$ of cases the duration of intervention was between 60 to 119 minutes. The average operative time was 102 minutes for the abdominally way and 90 minutes for vaginally surgery. According to Lansac [2], the duration of the vaginally hysterectomy is thirty-five to fourty-five minutes when an adnexectomy which extends the time of at least fifteen minutes is not realized. Our performance is well below those of literature and reflects our status of beginners in this field.

We recorded during our study five cases of bladder lesions (3.9\%) including two cases $(1.56 \%)$ by abdominally way and three $(2.34 \%)$ by vaginally way. Périneau [3] recorded on 1127 hysterectomies $1.2 \%$ of bladder injury abdominal and $1.7 \%$ vaginally. El Ghaoui [9] found on 962 hysterectomies $2.3 \%$ of bladder injury by abdominally and $1.5 \%$ by vaginally. Our experience shows an acceptable rate of bladder injury. This unusually high rate of $12.5 \%$ is explained by our status of beginner with vaginally hysterectomy.

The average hospital stay was 7 days with extremes of 1 to 27 . The study of hospital stay according to the indications clearly shows that the stay was signifi- 
cantly prolonged with obstetric indications $(p=0.003)$ and the presence of anemia at the admission $(\mathrm{p}<0.05)$. Our average stay is comparable to the data of the literature [3] [5] [10] [11] [12] [13] [14].

One hundred twenty-two patients were left without complication (95.3\%). For these patients the postoperative course was uneventful. Four cases $(3.12 \%)$ of death in all were recorded due to obstetric complications. It has concerned women in labor evacuated for uterine rupture (2 cases) and postpartum hemorrhage ( 2 cases). Périneau [3] recorded $0.9 \%$ death after total hysterectomy. About hysterectomies obstetric causes, Dongmo [12] found a mortality of 35\% in Yaoundé and Mayi-Tsonga [15] recorded a mortality of $24 \%$ in Libreville. Our fatality rate, higher than Périneau [3] can be explained by the fact that the deaths have been in cases of obstetric emergencies evacuated from peripheral structures in poor conditions.

\section{Conclusion}

Hysterectomy remains a major intervention in gynecology and obstetrics. It is marked by complications because very often practiced in a context of emergency with patients in poor general health condition. Improving the accessibility and affordability of health structures, the fight against poverty and monitoring delivery of labor by partogram could contribute to a sharp reduction in obstetric indications for hysterectomy. In contrast, the development of precancerous and cancerous lesions screening policies of the cervix should result in increased gynecological causes of hysterectomies.

\section{References}

[1] Cosson, M., Switala, I., Delest, A., Querleu, D. and Crepin, G. (1994) The Incision Hysterectomy for Benign Uterine Lesions without Prolapse. Study of a Continuous Series of 806 Cases. Revue francaise de gynecologie et d'obstetrique, 94, 17-24.

[2] Lansac, J., Body, G. and Magnin, G. (2002) Surgical Practice in Obstetrics and Gynecology. Masson, Paris, 360.

[3] Perineau, C., Monrozies, X. and Reme, J.M. (2002) Complications Hysterectomies. Revue francaise de gynecologie et d'obstetrique, 87, 120-125.

[4] Razafindrabe, J.A., Rabarijaona, M., Rakotoarisoa, B., Randriamaro, B., Sambany, R. and Razafindramboa, H. (2002) Reasons for Hysterectomy in Gynecology and Obstetrics. Médecine d'Afrique Noire, 49, 166-168.

[5] Dao, B., Toure, B., Sano, D., Bambara, M., Koalga, A., Da, E. and Bazie, A.J. (2001) Hysterectomies in Tropical Areas: Experience of an African Maternity. About 141 cases in Burkina Faso. Tunisia Medical, 79, 47-50.

[6] Lankoande, J., Sakande, B., Ouédraogo, A., Ouédraogo, C., Ouattara, T., Bonane, B. and Kone, B. (2002) Cervical Cancer in the Obstetrics and Gynecology Department of the National Hospital Yalgado Ouédraogo of Ouagadougou (Burkina Faso): Epidemiological, Clinical and Pathological Aspects. Black African Medicine, 45, 442-445.

[7] Kouakou, F., Anongba, S., Adjobi, R., N'Guessan, E., Tegnan, A., Guie, P., Kouyate, S., Osondu, J.N. and Coulibaly, K. (2002) Vaginal Hysterectomy Saharan Africa, a 
Necessary Development: About 15 Case. Journal of the $S A G O, 3,22-27$.

[8] Balima, E. (2002) Surgical Activities in Obstetrics Gynecology service of CHN-YO Ouagadougou. Stock of Five Years from January 1996 to December 2000. Thesis Med. UFR/SDS, Ouagadougou, No. 28, 67.

[9] Ghaoui El, A., Parant, O., Monrozies, X., Reme, J.M., Tanguy, Y. and Perineau, C. (2009) Vaginal Hysterectomy for Fibroid about 453 Cases. Retrospective Comparison to 509 Abdominal Hysterectomies. Annales De Chirurgie, 53, 201-205.

[10] Bashir, R., Parveen Sultana, R. and Khan, B. (2005) Two Years Audit of Complications of Hysterectomy at Ayub Teaching Hospital Abbottabad. Journal of Ayub Medical College Abbottabad, 17, 47-49.

[11] Dancoisne, P., Abossolo, T., Orvain, E., Tuaillon, J., Somer, J.C., Riviere, J.P. and Amat, D. (1994) Selection Criteria for Vaginal Hysterectomies during for Injuries Other Than Invasive Cancer. Revue francaise de gynecologie et d'obstetrique, $\mathbf{8 9}$, 11-14.

[12] Dongmo, R., Doh, A.S., Ngossa, M. and Temgoua, P. (2015) Obstetric Emergency Hysterectomy: About 31 Cases at the Hospital of Yaounde Cameroon. Congo Médical, 3, 46-54.

[13] Kouam, L., Kamdom-Moyo, J. and Ngassa, P. (1996) Indications and Complications of Vaginal Hysterectomy: A Beginner Experience on 24 Cases at the Hospital of Yaounde (Cameroon). Revue francaise de gynecologie et d'obstetrique, 91, 228-232.

[14] Subtle, D., Guttila, J.C. and Wattrisse, G. (1993) The Duration of Postoperative Hospitalization Gynecology. Journal de Gynécologie Obstétrique et Biologie de la Reproduction, 22, 18-23.

[15] Mayi-Tsonga, S., Pither, S., Meye, J.F., Ogowet, N., Ndombi, I., Nkiu, M. and Faye, A. (2002) Emergency Obstetric Hysterectomy: About 58 Cases at Libreville Hospital Centre. Medical Guinea No 38 October-November-December 2002, 8-12. 